\title{
MOLECULAR CHARACTERIZATION AND EXPRESSION ANALYSIS OF OREOCHROMIS NILOTICUS SERPIND1 (HEPARIN COFACTOR II) CDNA
}

\author{
ABEER A.I. HASSANIN ${ }^{1,2}$ and YOSHIO KAMINISHI ${ }^{2}$ \\ ${ }^{1}$ Department of Animal Wealth Development, Faculty of Veterinary Medicine, Suez Canal University, Ismailia, Egypt. \\ ${ }^{2}$ Laboratory of Marine Biotechnology, Faculty of Fisheries, Kagoshima University, Kagoshima, Japan.
}

Received: 30 June 2019; $\quad$ Accepted: 31 July 2019

\begin{abstract}
Heparin cofactor (HCII) is a member of serine protease inhibitors (SPIs) family of genes which play a fundamental physiological role in different biological processes including hemostasis. Therefore, this study aimed to cloning a partial nucleotide sequence of Nile Tilapia HCII cDNA and examine its expression level in the liver tissue following the intracoelomic injection of benzo-a-pyrene BaP. The cloned nucleotide sequence contained 972 bp representing a 666 bp of the Open Reading Frame (ORF) encodes for 221 amino acids and a stop codon and a $306 \mathrm{bp}$ of the $3^{\prime}$ noncoding region. The amino acids sequence comparison and phylogenetic tree analysis showed a close relationship between tilapia and Pundamilia nyererei serpind1 sequences. Realtime-PCR results showed high expression level (6.2) of Serpind1 mRNA in the liver of the BaP-treated fish compared with the control group suggesting the physiological role of HCII in tilapia. The study proposed the use of tilapia fish as a mammalian hemostasis model depending on the hemostatic genes homology analysis.
\end{abstract}

Key words: HCII, Nile Tilapia, BaP, Cloning, Realtime-PCR.

\section{INTRODUCTION}

Serine Proteinase INhibitors (Serpins) are a huge family of protease inhibitors having around 350-400 amino acids length. Most of the serpin family members involved in angiogenesis, blood coagulation, inflammation, and tumor suppression through inhibiting the activity of serine proteases (SPs) (Heit et al., 2013). Some serpins playing an immense role in migration, phagocytosis, and elimination of cancerous cells (Mangan et al., 2008).

'SERPIN' was designated as the gene symbol for humans and other species. Based on phylogenetic relationships, the serpin superfamily is divided into 16 clades named A-P, with clades A-I representing human serpins (Silverman et al., 2001). There are a variety of members being in each clade, for example, in the symbol SERPINA1, the ' $A$ ' referencing the clade and the ' 1 ' is the gene number within the clade (Wright, 1993). Up to date, around 3000 serpin genes were cloned from many species, including higher animals, plants, and viruses (Gagaoua et al., 2015).

Corresponding author: Dr. Abeer A.I. Hassanin

E-mail address: drabeer2000@gmail.com

Present address: Department of Animal Wealth Development, Faculty of Veterinary Medicine, Suez Canal University, Ismailia, Egypt
The Heparin Cofactor II (HCII) gene (known as SERPIND1 in humans) is a serpin that belongs to clade D or group 2. It has been characterized in many vertebrate species, such as humans, rabbit, cow, African clawed frog, European flounder, and zebrafish (http://www.ncbi.nlm.nih.gov/entrez/). The main function of HCII is inhibiting thrombin (Parker and Tollefsen, 1985). Thrombin is involved in many physiological processes including coagulation, and thus HCII controls all the biochemical processes in which thrombin is involved (He et al., 2002).

Nile Tilapia (Oreochromis niloticus) is an African freshwater cichlid which affected by toxicants that exist as complex mixtures closely associated with the sediment such as heavy metals and polycyclic aromatic hydrocarbons (PAHs). Benzo-a-pyrene $(\mathrm{BaP})$ is an omnipresent Polycyclic Aromatic Hydrocarbon (PAH) which generated as a byproduct of organic combustion and has gotten the foremost consideration in fish species, with a major focus on hepatic metabolism (Varanasi et al., 1989). Previous studies showed the Carcinogenic effect of BaP to fish following oral (Hendricks et al., 1985) and waterborne exposures (Hawkins et al., 1988).

$\mathrm{BaP}$ is a ligand of the aryl hydrocarbon receptor (AHR), a ligand-activated transcription factor found in the inactive form as a cytosolic complex with two $90 \mathrm{kDa}$ heat shock proteins (HSP90) and c-SRC protein kinase (Meyer and Perdew, 1999). Upon ligand binding, AHR dissociates from the heteromeric 
complex and translocates into the nucleus to dimerize with the AHR nuclear translocator (ARNT) to form the ligand-bound AHR/ARNT complex. The ligand/AHR/ARNT complex recognizes and binds to specific xenobiotic responsive elements leading to the transcriptional activation of several genes including members of the cytochrome P450 family of enzymes (e.g. CYP1A1, CYP1B1) which in turn catalyze the conversion of $\mathrm{BaP}$ into reactive metabolic intermediates.

The use of molecular biomarkers such as gene expression changes in the field of marine environmental monitoring playing an important role in recognition of exposure and impact of different pollutants (Malins and Ostrander, 1994). Although Serpins are a group of extensively studied protease inhibitors (Harish and Uppuluri, 2017), there is very little information about their role in Oreochromis niloticus. Therefore, the present study aimed at cloning of partial serpind1 cDNA sequence from the liver of Oreochromis niloticus fish following the intraperitoneal injection of benzo (a) pyrene (BaP) and investigate $\mathrm{BaP}$-induced serpind1 gene expression in liver tissue of the same fish. This will facilitate future research on the structure of serpind1 gene family in tilapia fish and the molecular mechanisms by which BaP affecting the homeostasis process in tilapia.

\section{MATERIALS AND METHODS}

\section{Experimental fish}

Thirty male nile tilapia ( $500 \pm 10 \mathrm{~g})$ were provided by a local fish farm in Japan. Fish were acclimated for one week at $28{ }^{\circ} \mathrm{C}$ with normal feeding. After the acclimatization period, fish were divided into control and treated groups with 15 fish in each group. The treated group were injected intracoelomically with $\mathrm{BaP}(100 \mathrm{mg} / \mathrm{kg}$ body weight) while the fish in the control group were injected with the corn oil as a vehicle. One day after the injection, fish in both groups were sacrificed; liver samples were taken, stored in liquid nitrogen at $-80^{\circ} \mathrm{C}$ till analysis.

\section{Molecular Characterization of a partial tilapia Serpin1D1 cDNA sequence.}

\subsection{RNA extraction and Reverse transcription}

Isogen reagent (Nippon Gene Co., LTD.) was used for total RNA extraction from the liver tissue of tilapia according to the manufacture's protocol. Spectrophotometer was used to assess the RNA samples purity and concentration as described by Sambrook and Russel (2001), A260/A280 ratio ranging from 1.7 and 1.9. cDNA was synthesized using Superscript II reverse transcriptase (GibcoBRL, USA) to generate 5'-RACE-Ready and 3'RACE-Ready first strand cDNA using a SMART ${ }^{\mathrm{TM}}$ RACE cDNA amplification kit (Clontech, USA) according to the manufacture's protocol.

\subsection{Oligonucleotide primers and PCR amplification of Tilapia Serpin1D1 cDNA}

Two primer sequences, sense (F) and antisense (R), were designed using highly conserved regions of different fishes serpind1 sequences retrieved from GenBank/NCBI data bank. The primers sequences are; Forward primer (5'- AAGAGTGTGGATCC AAATATGG -3'), reverse primer (5'AGAAATGACTGTTTCACTTCAGCC-3') .PCR reaction was carried out in a final volume of $25 \mu 1$ containing the DNA sample $(1 \mu \mathrm{l})$, forward and reverse primers $(1 \mu 1$ each), PCR master mix $(12.5 \mu \mathrm{l})$ and distilled water $(9.5 \mu \mathrm{l})$. The cycle conditions were as follows: initial denaturation at $94^{\circ} \mathrm{C}$ for 5 minutes, 35 cycles of $94^{\circ} \mathrm{C}$ for $30 \mathrm{sec}, 60^{\circ} \mathrm{C}$ for $30 \mathrm{sec}$ and $72^{\circ} \mathrm{C}$ for $1 \mathrm{~min}$, then $72^{\circ} \mathrm{C}$ for 5 minutes for further extension. The PCR product was electrophoresed on $1 \%$ agarose gel and the resulting fragments were visualized by UV transillumination. The DNA band of the 972 bp length was excised, purified using GFX PCR DNA and a gel band purification kit (GE Health Care, UK), cloned into PT7BlueT- vector (Novagen, USA). Direct sequencing for the Purified plasmids was done by dye terminator cycle sequencing using an ABI PRISM dye terminator cycle3130 xl DNA sequencer.

\subsection{Phylogenetic analysis of tilapia Serpin1D1}

The following serpind1 mRNA sequences were retrieved from the Genbank and used to assess the phylogenetic tree of serpin1D1 gene family; XM_026186216 (Astatotilapia calliptera serpind1), XM_012865588 (Fundulus heteroclitus serpind1), XM_005924414 (Haplochromis burtoni serpind1),XM_017412364 (Kryptolebias marmoratus serpind1),XM_004547002 (Maylandia zebra srpind1), XM_011478884(Oryzias latipes serpind1), XM_024275125(Oryzias melastigma serpind1), XM_028577377 (Perca flavescens serpind1), XM_005738200 (Pundamilia nyererei serpind1)

\section{Serpind1 gene expression in tilapia liver after} intracoelomic injection of BaP.

RT-qPCR was used to detect the transcript expression pattern of liver- serpind1. The reaction was done using Fast Start Essential DNA Green Mater (Roche, 06402712001) and LightCycler Nano system (Roche Applied Science). $\beta$-actin was utilized as an internal reference gene for expression analysis. Primer sequences for both tilapia serpind 1 and $\beta$-actin genes were listed in Table 1 . Cycle conditions were as follows; one cycle of $95^{\circ} \mathrm{C}$ for $10 \mathrm{~min}, 35$ cycles of $95^{\circ} \mathrm{C}$ for $10 \mathrm{sec}, 60^{\circ} \mathrm{C}$ for $10 \mathrm{sec}, 72^{\circ} \mathrm{C}$ for $15 \mathrm{sec}$, one cycle of $95^{\circ} \mathrm{C}$ for $30 \mathrm{sec}$; and one cycle of $60^{\circ} \mathrm{C}$ for $20 \mathrm{sec}, 95^{\circ} \mathrm{C}$ for $20 \mathrm{sec}$. The geometric mean of the internal control genes was used in the quantification analysis of gene expression according to Hellemans equation (Hellemans et al., 2007). 


\section{RESULTS}

\section{Tilapia serpind1 cDNA partial sequence} analysis.

Partial cDNA sequence of serpind1 was characterized in tilapia (Oreochromis niloticus). The sequence contained 972 bp representing a 666 bp of the Open Reading Frame (ORF) which encoding for 221 amino acids and a stop codon and a 306 bp of the 3' noncoding region (Figure 1). Sequence alignment of this sequence with the previously mentioned sequences was done by Clustal W (Thompson et al., 1994) using Lasergene Megalign program, version 15, 2018 (DNASTAR Inc) and has been registered in the GenBank/NCBI data bank with an accession number MN117958.

\section{Amino acids sequence comparison}

The comparison of amino acid sequences of tilapia serpind 1 protein with that of the other species mentioned earlier presented in Table 2. The results recorded that the tilapia serpind 1 sequence is closest to that of the Pundamilia nyererei fish (97.6) while the lowest identity was found with Oryzias latipes fish (69.2).

\section{Phylogenetic analysis of tilapia serpind1 protein.}

A phylogenetic tree was constructed between the amino acid sequences of serpins through Clustal W (Thompson et al., 1994) using Lasergene Megalign program, version 15, 2018 (DNASTAR Inc). Figure 2 clearly shows a close relationship between tilapia serpind 1 and Pundamilia nyererei serpind 1.

\section{Realtime-PCR results}

The results show high expression level (6.2) of Serpind 1 mRNA in the liver of the BaP-treated fish compared (Figure 3) with the control group with almost no expression detected in other tissues (gills, heart, muscle, intestine, data not shown here).

Table 1: Real-time PCR primers of tilapia serpind1 and $\beta$-actin genes.

\begin{tabular}{cccc}
\hline \multirow{2}{*}{ Gene } & Primer description & Sequence (5'-3') & \multirow{2}{*}{ Product size } \\
\hline \multirow{2}{*}{ Serpind1 } & $\mathrm{F}$ & 5'-CTCCCTTACATAACTCAAAGCACA-3' & \multirow{2}{*}{$117 \mathrm{bp}$} \\
\cline { 2 - 3 } & $\mathrm{R}$ & 5'-AGAAGCGTGCTCAGAAAACAG-3' & \\
\cline { 2 - 3 }$\beta$ - actin & $\mathrm{F}$ & 5'-GGGTCAGAAAGACAGCTACGTT-3' & \multirow{2}{*}{$143 \mathrm{bp}$} \\
\cline { 2 - 3 } & $\mathrm{R}$ & 5'-CTCAGCTCGTTGTAGAAGGTGT-3 & \\
\hline
\end{tabular}

Table 2: Percent identities of deduced amino acid sequences of serpind1 gene subfamilies.

\begin{tabular}{|c|c|c|c|c|c|c|c|c|c|}
\hline & $\begin{array}{c}\text { P. } \\
\text { nyererei }\end{array}$ & $\begin{array}{c}\text { A. } \\
\text { calliptera }\end{array}$ & $\begin{array}{c}\text { F. } \\
\text { heteroclitus }\end{array}$ & $\begin{array}{c}\text { H. } \\
\text { burtoni }\end{array}$ & $\begin{array}{c}\text { K. } \\
\text { narmoratus }\end{array}$ & $\begin{array}{c}\text { M. } \\
\text { zebra }\end{array}$ & $\begin{array}{c}\text { O. } \\
\text { latipes }\end{array}$ & $\begin{array}{c}\text { O. } \\
\text { melastigma }\end{array}$ & $\begin{array}{c}\text { P. } \\
\text { flavescens }\end{array}$ \\
\hline O. niloticus & 97.6 & 96.9 & 76.2 & 96.6 & 77.9 & 96.7 & 69.2 & 70.9 & 83.2 \\
\hline P. nyererei & & 99.7 & 82.0 & 99.3 & 84.6 & 99.7 & 81.4 & 80.4 & 86.2 \\
\hline A.calliptera & & & 78.1 & 99.2 & 80.7 & 100.0 & 76.4 & 75.9 & 83.7 \\
\hline F. heteroclitus & & & & 75.7 & 83.2 & 76.2 & 72.7 & 73.2 & 80.5 \\
\hline H. burtoni & & & & & 78.8 & 99.1 & 73.5 & 73.5 & 83.5 \\
\hline K.marmoratus & & & & & & 78.9 & 72.9 & 73.6 & 82.5 \\
\hline M.zebra & & & & & & & 73.4 & 73.4 & 83.7 \\
\hline O.latipes & & & & & & & & 86.5 & 79.7 \\
\hline O.melastigma & & & & & & & & & 79.5 \\
\hline
\end{tabular}




\section{Figure legend.}

Figure 1: Partial Nucleotide sequence (972 bp) of tilapia serpind1representing a 666 bp of the Open Reading Frame (ORF) which encoding for 221 amino acids and a stop codon and a $306 \mathrm{bp}$ of the 3'noncoding region.

Figure 2: Phylogenetic tree of serpind1 cDNAs using the amino acid sequences.

Figure 3: Serpind 1 mRNA levels in liver tissue of control and of BaP treated tilapia fish

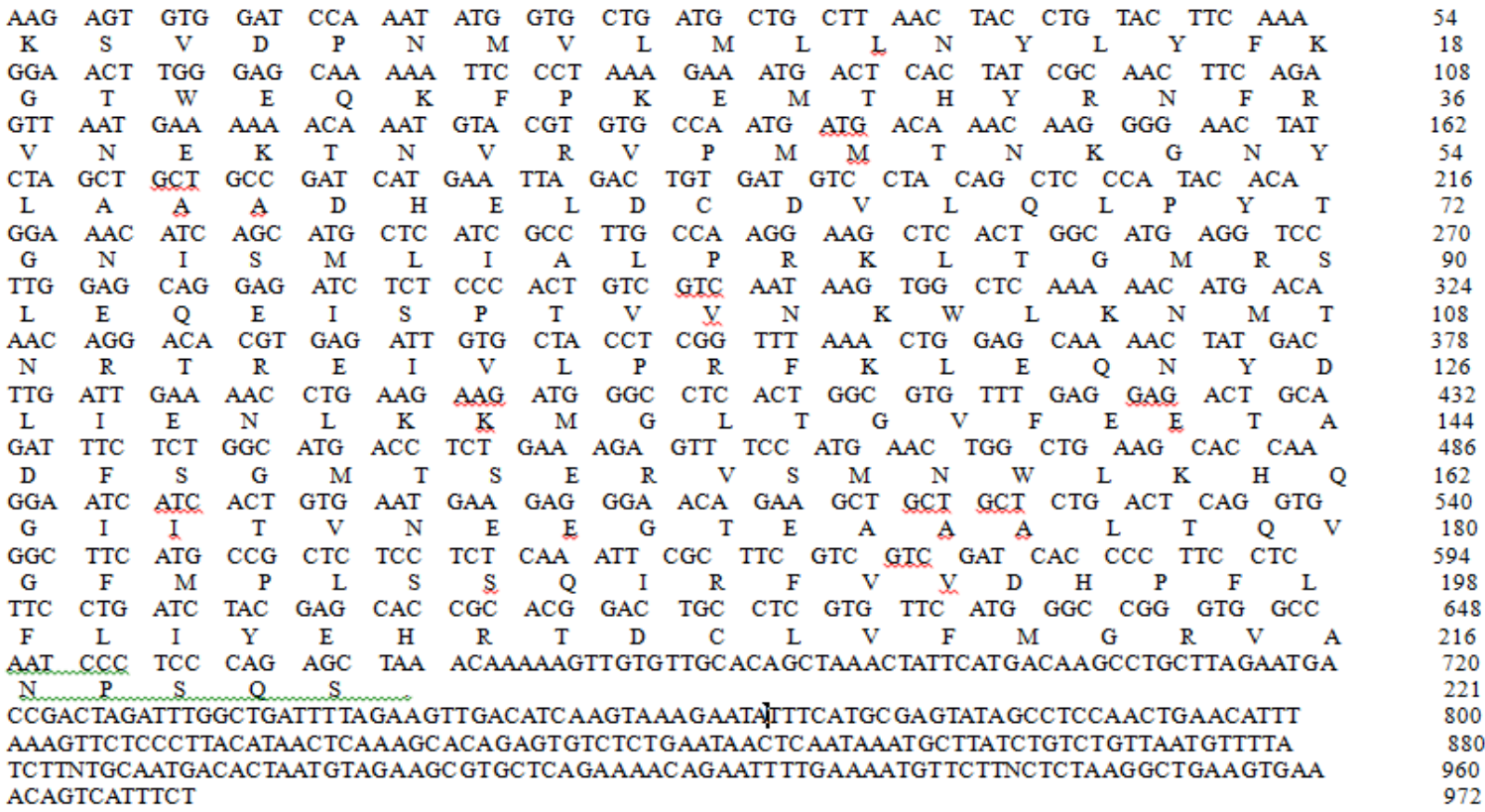

Figure 1:

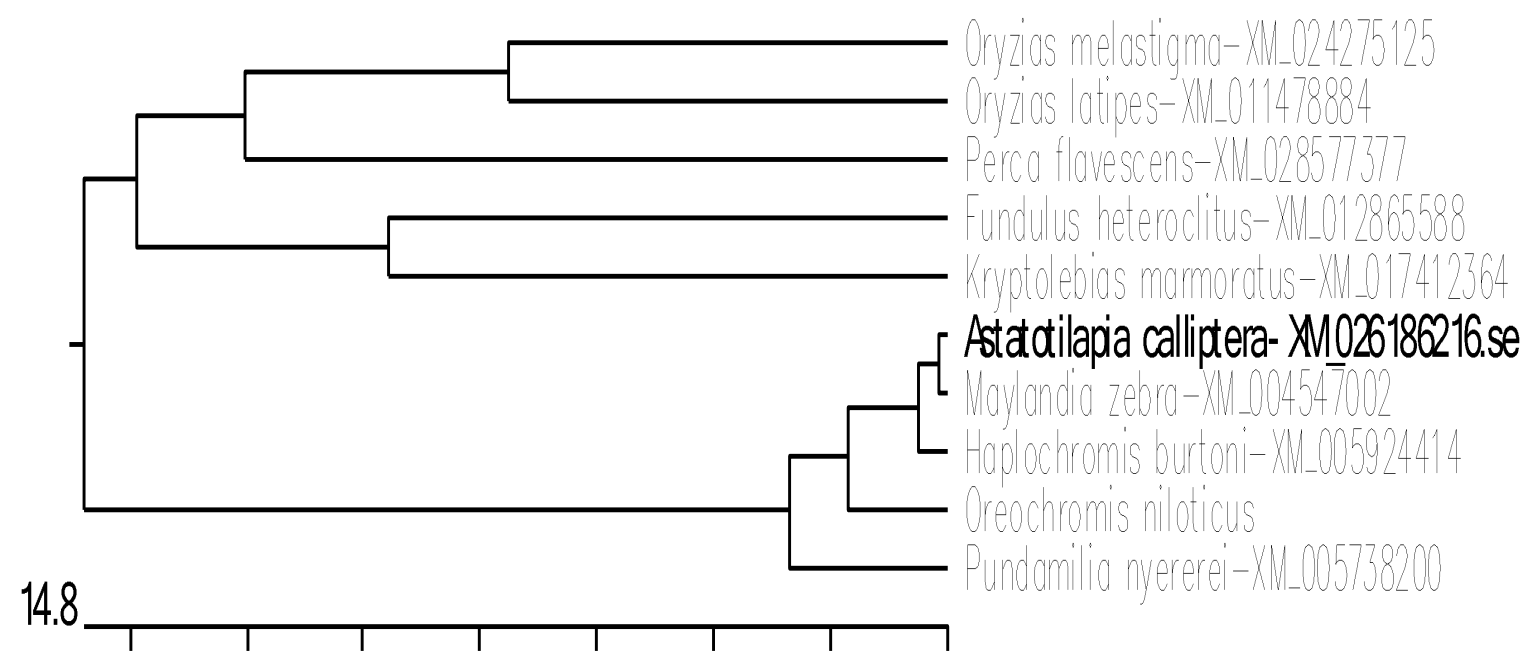

Figure 2: 


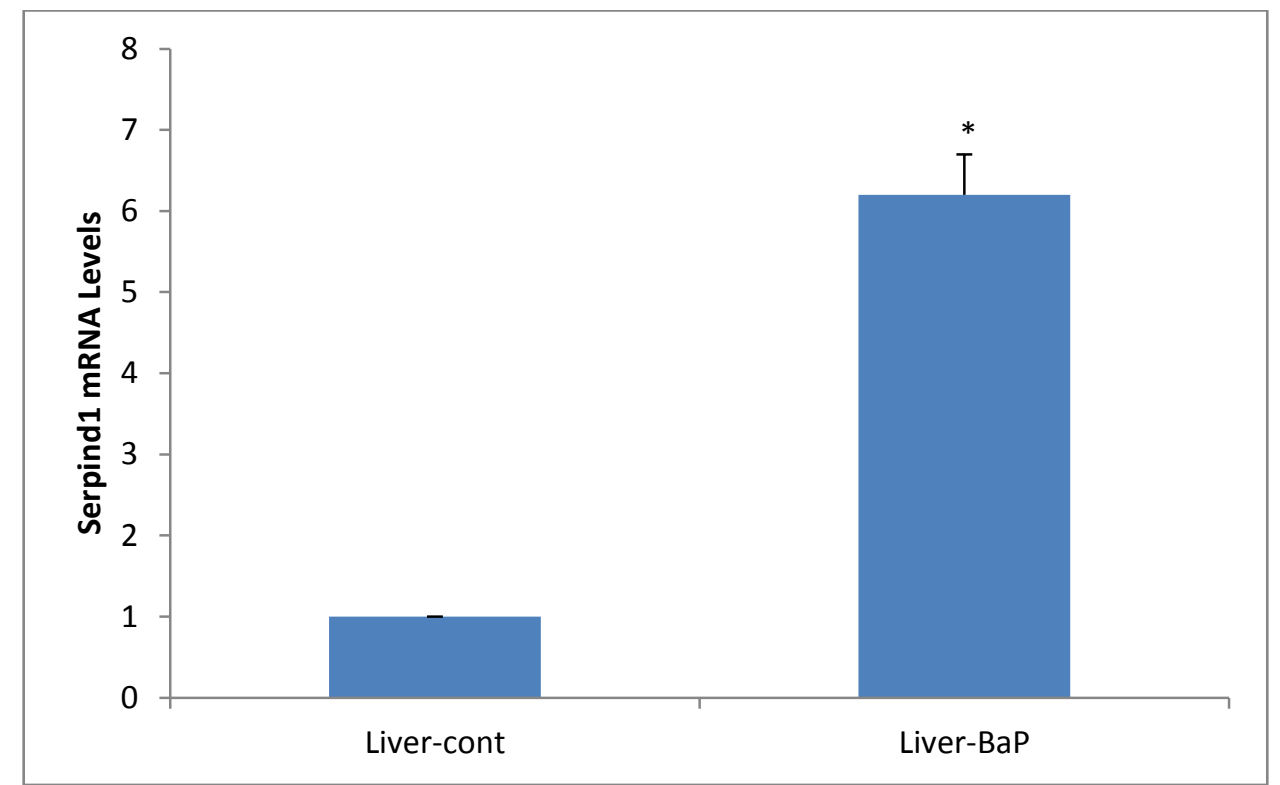

Figure 3:

\section{DISCUSSION}

The Serine proteinase inhibitors (Serpins) superfamily playing an important role in many fundamental biological processes including blood coagulation, cell, cell migration, inflammation, angiogenesis, and tumor suppression (Kumar, 2009).

Hemostasis (the process which causes the bleeding stop) is a feature by which the vertebrates respond to vascular injury and pathophysiology (Umasuthan et al., 2001). Serpins including HCII are involved in different biochemical pathways of hemostasis (Umasuthan et al., 2001). The biochemical properties HCII have been well studied in mammals. However, in lower-order vertebrates such as the teleost, there is rare information about both molecular structure and physiological role of this gene. Realtime-PCR results indicated higher expression of HCII mRNA in the liver samples of fish treated with $\mathrm{BaP}$ compared with the control samples.

In this study, a partial sequence of heparin cofactor II cDNA was cloned and characterized in nile tilapia fish and its transcription response in the liver was investigated after the intracoelomic injection of $\mathrm{BaP}$. The phylogenetic tree revealed a close relationship between tilapia HC II and Pundamilia nyererei HCII. There is an agreement between the order displayed in the tree and the evolutionary order of the species involved, the sequence homology and the phylogenetics confirm that tilapia HCII belongs to the teleost serpin, clade D.

Several studies stated that a major amount of HCII mRNA is transcribed in the human liver (Kamp et al.,
2001). Similar results were obtained in our study indicate that the liver contributes to a large extent of circulatory HCII.

Liver is the main organ for $\mathrm{BaP}$ metabolism in fish causing the formation of carcinogenic metabolites and cytotoxicity (Andersson and Koivusaari 1985; Gill and Walsh 1990). After intraperitoneal injection, the maximum level of the $\mathrm{BaP}$ was reached in the fish liver after $6 \mathrm{~h}$, then decrease gradually until $24 \mathrm{~h}$, followed by new increased bioaccumulation of liver $\mathrm{BaP}$ with the maximum metabolization level in the liver after only $24 \mathrm{~h}$ exposure. (Banni et al., 2009).

Thrombin is a serine protease enzyme which catalysis the conversion of fibrinogen into fibrin and so aids in the formation of a blood clot. It transduces signals through protease-activated receptors (PARs) to activate the neutrophils and platelets aiming at enhancing the release of pro-inflammatory factors such as chemotactic agents, cytokines and growth factors (the mediators affect the inflammation). This explains how coagulation proteases and inhibitors including HCII associated with the inflammation by controls thrombin activity (Shrivastava et al., 2007).

In conclusion, this is aimed at identification and characterization of a partial sequence of novel heparin cofactor II (HCII) from nile tilapia (O. niloticus). Phylogenetic analysis showed high similarity between tilapia HCII and the clade D, HCII serpin members. Constitutive HCII mRNA expression was recorded in liver tissue following intraperitoneal injection of $\mathrm{BaP}$, suggesting its physiological importance. Our results proposed the use of tilapia fish as a mammalian 
hemostasis model depending on the hemostatic genes homology analysis.

\section{REFERENCES}

Andersson, T. and Koivusaari, U. (1985): Influence of environmental temperature on the induction of xenobiotic metabolism by b-naphthoflavone in rainbow trout, Salmo gairdneri. Toxicol Appl Pharmacol.; 80: 43-50.

Banni, M.; Bouraoui, Z. and Ghedira, J. (2009): Acute effects of benzo[a]pyrene on liver phase I and II enzymes, and DNA damage on sea bream Sparus aurata. Fish Physiol Biochem.; 35: 293-299.

Gagaoua, M.; Hafid, K. and Boudida, Y. (2015): Caspases and thrombin activity regulation by specific serpin inhibitors in bovine skeletal muscle, Appl. Biochem. Biotechnol.; 177 (2): 279-303.

Gill, K.A. and Walsh, P.J. (1990): Effects of temperature on metabolism of benzo[a]pyrene by toadfish (Opsanus beta) hepatocytes. Can J Fish Aquat Sci.; 47: 831-837.

Hawkins, W.E.; Walker, W.W. and Overstreet, R.M. (1988): Dose-related carcinogenic e!ects of water-borne benzo[a]pyrene on livers of two small "sh species. Ecotoxicol. Environ. Saf.; 16: 219-231.

Harish, B.S. and Uppuluri, K.B. (2017): Microbial serine protease inhibitors and their therapeutic applications, Int. J. Biol. Macromol.; 107 (Pt B): 1373-1387.

He, L.; Vicente, C.P. and Westrick, R.J. (2002): Heparin cofactor II inhibits arterial thrombosis after endothelial injury. J. Clin. Invest.; 109: 213-9.

Heit, C.; Jackson, B.C. and Mcandrews, M. (2013): Update of the human and mouse SERPIN gene superfamily. Hum. Genom.; 7 (1): 22.

Hellemans, J.; Mortier, G. and De Paepe, A. (2007): qBase relative quantification framework and software for management and automated analysis of real-time quantitative PCR data. Genome Biol.; 8: R19.

Hendricks, J.C.; Meyers, T.R. and Shelton, D.W. (1985): Hepatocarcinogenicity of benzo (a) pyrene to rainbow trout by dietary exposure and intraperitoneal injection. J. Natl. Cancer Inst.; 74: 839-851.

Kamp, P.; Strathmann, A. and Ragg, H. (2001): Heparin cofactor II, antithrombin-beta and their complexes with thrombin in human tissues. Thromb. Res.; 101: 483e91.
Kumar, A. (2009): Delving into Vertebrate Serpins for Understanding their Evolution. Nature Precedings: doi:10.1038/npre.2009.3050.1.

Malins, D.C. and Ostrander, G.K. (1994): Aquatic Toxicology: Molecular and Cellular Perspectives. Lewis, Boca Raton, FL.

Mangan, M.S.; Kaiserman, D. and Bird, P.I. (2008): The role of serpins in vertebrate immunity. Tissue Antigens; 72: 1-10.

Meyer, B.K. and Perdew, G.H. (1999): Characterization of the AhR-hsp90-XAP2 core complex and the role of the immunophilin-related protein XAP2 in AhR stabilization. Biochemistry; 38: 8907-8917.

Parker, K.A. and Tollefsen, D.M. (1985): The protease specificity of heparin cofactor II. Inhibition of thrombin generated during coagulation. J. Biol. Chem.; 260: 3501-3505.

Sambrook, J. and Russell, D. (2001): Molecular Cloning: A Laboratory Manual, 3rd edn. Cold Spring Harbor, NY: Cold Spring Harbor Laboratory Press.

Shrivastava, S.; McVey, J.H. and Dorling, A. (2007): The interface between coagulation and immunity. Am J Transplant.; 7: 499-506.

Silverman, G.A.; Bird. P.I. and Carrell, R.W. (2001): The serpins are an expanding superfamily of structurally similar but functionally diverse proteins: evolution, mechanism of inhibition, novel functions, and a revised nomenclature. $\mathbf{J}$ Biol Chem.; 276: 33293-33296.

Thompson, J.D.; Higgins, D.G. and Gibson, T.J. (1994): CLUSTAL W: improving the sensitivity of progressive multiple sequence alignment through sequence weighting, position-specific gap penalties and weight matrix choice. Nucleic Acids Res.; 22(22): 4673-80.

Umasuthan, N.; Whang, I. and Lee, W. (2011): Heparin cofactor II (RbHCII) from rock bream (Oplegnathus fasciatus): Molecular characterization, cloning and expression analysis. Fish \& Shellfish Immunology; 30: 194-208

Varanasi, U.; Stein, J.E. and Nishimoto, M. (1989): Biotransformation and disposition of polycyclic aromatic hydrocarbons (PAH) in fish. In: Varanasi U (ed), Metabolism of Polycyclic Aromatic Hydrocarbons in the Aquatic Environment, pp 93-150. CRC Press, Boca Raton, FL, USA.

Wright, H.T. (1993): Introns and higher-order structure in the evolution of serpins. J. Mol. Evol.; 36: 136-143. 


\section{استنساخ وتحديد التتابع النيوكلوتيدى ودراسة التعبير الجينى لثريط الحمض النووى المكمل للفصيلة D من العائلة الميلي لفوق فصيلة Serpin في أسماك البلطى النيلى}

هو واحد من جينات عائلة جين ال Serpin المسئولة عن معظم العمليات الحيوية داخل الجسم فيما فيها عملية وقف النزف.

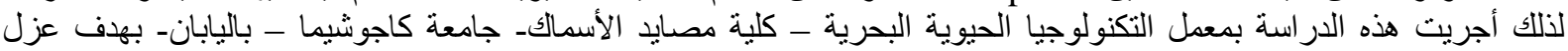

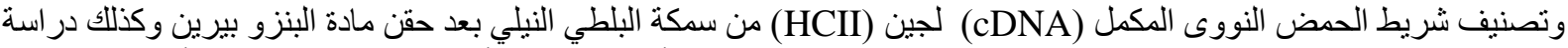

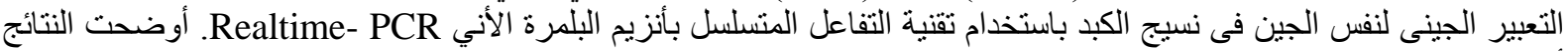

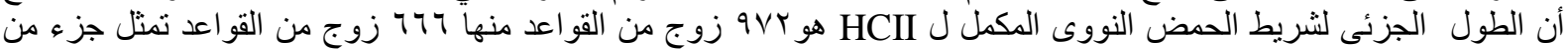

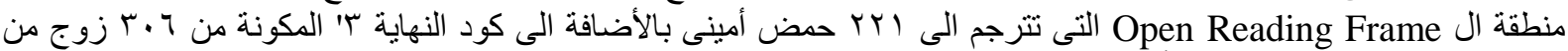

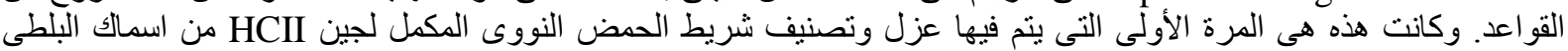

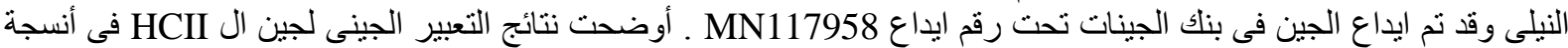

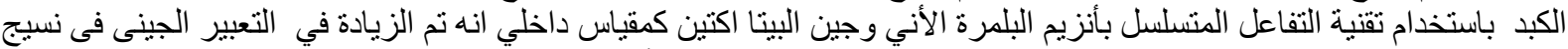

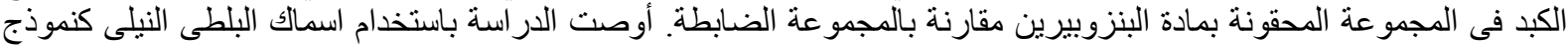

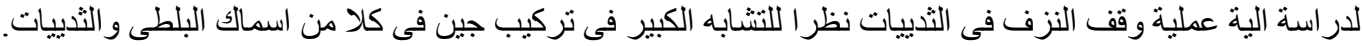

